\title{
Reflexões sobre a formação do enfermeiro no contexto do Sistema Único de Saúde
}

\author{
Lucieli Dias Pedreschi Chaves, D.Sc.*, Ana Lídia de Castro Sajioro Azevedo**
}

*Enfermeira, Professora do Departamento de Enfermagem Geral e Especializada, da Escola de Enfermagem de Ribeirão Preto -USP, **Enfermeira, Mestranda em Enfermagem Fundamental na EERP-USP, Especialista da Escola de Enfermagem de Ribeirão Preto-USP, Universidade de São Paulo.

\section{Resumo}

O cenário atual do Sistema Único de Saúde (SUS) exerce expressiva influência no processo de formaçáo dos enfermeiros. A partir da normatização educacional vigente e produção científica sobre a temática, este artigo tem como objetivo apresentar reflexôes acerca da formação do enfermeiro no contexto do SUS, evidenciando limitaçóes e pontos críticos. Para atingir este objetivo apresenta em sua introduçáo generalidades sobre educação e recursos humanos em saúde, perpassando pelos aspectos da formação profissional para o SUS, para em seguida abordar as especificidades da formaçáo do enfermeiro. Está em curso uma mudança no ensino de enfermagem que busca consolidar a formação na perspectiva de atuaçáo do enfermeiro de maneira crítica, reflexiva, inovadora e competente, como membro de equipe multiprofissional. O momento é de construçáo de uma nova realidade, considerando limitaçóes e potencialidades de cada instituição de ensino, vencendo desafios relacionados à estrutura universitária e ao próprio processo.

Palavras-chave: educação em enfermagem, enfermagem, educação, recursos humanos.

\section{Abstract \\ Thinking about nurses education on the Unified Health System context}

The current structure of the Unified Health System (UHS) exerts expressive influence in nurses educational process. From the existing rules regarding education and the scientific production on the theme, this article aims to develop thoughts regarding nurses training in the context of UHS, showing limitations and critical points. In order to achieve its aim, firstly introduces general aspects of education and human resources on health, secondly approaches specificities of nurses education. Changes in nursing teaching are in progress aiming to consolidate training in the perspective of nurses performance in a critical, reflexive, innovative and competent way, as member of multiprofessional team. It is time to build a new reality, considering limits and potentiality of each teaching institution, to overcome challenges related to university structure and the process itself.

Key-words: education, nursing; nursing; education; human resources. 


\section{Resumen}

\section{Reflexiones sobre la formación del enfermero en el contexto del Sistema Único de Salud}

El actual escenario del Sistema Único de Salud (SUS) ejerce expresiva influencia en el proceso de formación de los enfermeros. A partir de las normas de educación vigentes y producción científica acerca de la temática, el artículo objetiva presentar una reflexión acerca de la formación del enfermero en el contexto del SUS, evidenciando limitaciones y puntos críticos. Para atingir ese objetivo presenta generalidades sobre educación y recursos humanos en salud y aspectos de la formación profesional para el SUS. Trae también especificidades de la formación del enfermero y presenta otras consideraciones. Están en desarrollo cambios en la enseñanza en enfermería que buscan consolidar la formación del enfermero para actuar de manera crítica, reflexiva, innovadora y competente, como miembro de equipos multiprofesionales. Es momento para la construcción de una nueva realidad, considerando limitaciones y potencialidades de cada institución de enseñanza, venciendo desafíos relacionados a la estructura universitaria y al propio proceso.

Palabras-clave: educación en enfermería, enfermería, educación, recursos humanos.

\section{Introdução}

Refletir sobre a formação do enfermeiro requer entender o contexto de reorganização do sistema de saúde brasileiro, que é responsável pela definição e implementação da política de recursos humanos (RH) em saúde, que em última instância viabilizará a concretização do próprio Sistema Único de Saúde (SUS).

O objetivo maior do sistema de saúde diz respeito à saúde das pessoas nos aspectos de promoção, prevenção, recuperação e reabilitação, justificando o investimento de recursos na formação, qualificação e capacitação dos trabalhadores/profissionais com vistas a atingir este objetivo.

Define-se trabalhadores da saúde como todas as pessoas engajadas na prestaçáo de serviços de saúde à populaçáo e que têm o propósito fundamental de reconstruir no cotidiano, as concepçôes teóricas e práticas em torno da atenção a saúde. Estes trabalhadores fazem parte de equipes funcionais, as quais têm responsabilidades e tarefas específicas, desempenhando funçôes que são articuladas entre si [1].

A relevância dos trabalhadores/profissionais da saúde fica evidente quando são considerados sujeitos e objetos do processo de efetivação dos princípios do SUS. Neste sentido, destaca-se a responsabilidade da gestáo com a formação e desenvolvimento de recursos humanos.

Os processos educacionais abarcam aspectos relativos ao desenvolvimento de recursos humanos e formação de futuros profissionais, trata-se de processos distintos, porém imbricados e que apresentam interfaces. A educação vinculada à experiência de emprego no setor pode ter várias denominaçôes educação continuada, educação permanente, reciclagem, aperfeiçoamento e motivação, compondo o aspecto denominado desenvolvimento de $\mathrm{RH}$. Os aspectos referentes aos processos educativos formais que conferem certificação/habilitação profissional específica, voltada ou não para o pessoal de serviço dizem respeito à formação de recursos humanos [2].

Cabe destacar que o desenvolvimento de recursos humanos abarca as ações de educação continuada e permanente em uma perspectiva de constante qualificação dos trabalhadores da saúde e a formação de futuros profissionais também se faz presente no cenário dos serviços de saúde nos quais os estudantes têm oportunidade de desenvolver habilidades e competências a partir de vivencias no mundo do trabalho. No dia-a-dia dos serviços de saúde, os aspectos de desenvolvimento e formação de recursos humanos apresentam intersecçóes, como por exemplo, uma das etapas do processo de formação de futuros enfermeiros pode ser produzir coletivamente atividades educativas para trabalhadores de saúde de determinada unidade de saúde que serve como cenário para atividades teórico-práticas.

Embora reconhecendo esses dois aspectos relativos aos processos educacionais como interligados, neste artigo o foco é o processo de formaçáo de futuros enfermeiros.

Os enfermeiros constituem uma categoria profissional com expressivo contingente de trabalhadores e significativa participação na atenção em saúde nas diferentes esferas do SUS, justificando essa abordagem mais específica acerca de sua formação. 
Acredita-se que a análise da legislação educacional vigente e da produção científica sobre a temática, aliada a vivência profissional das autoras em uma instituição de ensino possa trazer contribuições para as discussóes sobre a formação do enfermeiro no contexto do SUS. Neste sentido o objetivo deste estudo é apresentar, no cenário atual, uma reflexão acerca da formação de enfermeiros evidenciando limitações e pontos críticos.

O presente artigo apresenta em sua introdução generalidades sobre educação e recursos humanos (RH), perpassando pelos aspectos da formação profissional para o SUS, para em seguida abordar a especificidade da formação do enfermeiro e apresentar as consideraçóes finais.

\section{A formaçáo profissional para o SUS}

Embora a $8^{\text {a }}$ Conferência Nacional de Saúde de 1986, a Constituição Federal de 1988, a Lei Orgânica de Saúde, as Normas Operacionais Básicas, as Normas Operacionais de Assistência à Saúde e as Normas Operacionais Básicas de Recursos Humanos - SUS determinem as atribuiçóes das três esferas de governo, relativas às políticas de recursos humanos e educação, estas normativas ainda hoje não garantem açôes/estratégias resolutivas e que se efetivem no cotidiano.

É importante destacar, que historicamente, o tema recursos humanos em saúde teve pouca relevância na política de saúde vigente no Brasil antes da implantação do SUS, sendo tratado como uma questão de menor interesse e repercussão [3].

$\mathrm{Na}$ década de 90 parecia haver uma preocupação social que se traduzia em não reconhecer no recurso humano apenas um fator de produção, mas sim um elemento fundamental para a transformação dos processos produtivos, havendo necessidade de resgatar a vontade dos indivíduos, grupos e coletividade para a elaboração ou a proposição de projetos novos. Ainda hoje, as alteraçôes legais, políticas e administrativas na área da saúde não contemplaram suficientemente os sujeitos que operam e usufruem estas mudanças [4].

A Constituição Federal de 1988 firmou que as ações e os serviços de saúde, constituídos em sistema único, integram uma rede organizada segundo diretrizes, dentre elas a integralidade da atenção e, determina que a competência para ordenar a formação de recursos humanos na área da saúde é do SUS. A Lei Orgânica da Saúde destaca que a política para os trabalhadores do setor saúde deve cumprir o objetivo de organizar um sistema de formação em todos os níveis de ensino, inclusive pós-graduação e programas permanentes de aperfeiçoamento de pessoal [5].

Pensar em uma articulação entre sistema educacional e sistema de saúde para formação de recursos humanos parece lógico; entretanto, no Brasil, esta ainda é uma realidade frágil, que nos últimos anos tem avançado, mas há muito para ser construído.

A organização social dos serviços de saúde influencia o perfil dos futuros profissionais, mas ao mesmo tempo as instituiçóes de ensino são responsáveis pela formaçáo de profissionais que vão interferir na organização dos serviços, facilitando ou dificultando as transformaçóes necessárias para o fortalecimento do SUS, ou seja, o sistema de saúde e a formação profissional estáo intimamente ligados, embora na prática esta articulação ainda seja incipiente [6].

Pode-se dizer que há um consenso entre os críticos da educação dos profissionais da saúde em relação à hegemonia da abordagem biologicista, medicalizante e procedimento-centrada presentes na formação; cujo modelo pedagógico predominante é centrado em conteúdos, organizados em compartimentos fragmentados, que dissocia conhecimentos da área básica daqueles da área clínica, centra oportunidades de aprendizagem em hospitais universitários, adota sistemas de avaliação cognitiva por acumulação de informação técnicocientífica padronizadas, estimula a especializaçáo precoce, perpetua modelos tradicionais de atenção à saúde, ou seja, a perspectiva tradicional da educação superior praticamente desconhece estratégias didático-pedagógicas que favoreçam a participação ativa dos estudantes [7].

Embora os currículos, centrados em conteúdos mínimos e disciplinas, mostrem-se inadequados face às mudanças sociais, às demandas dos serviços, às necessidades de saúde da população e ao perfil epidemiológico vigente, ainda hoje são realidade em muitas instituiçóes de ensino. Desse modo, evidencia-se que o perfil de formaçáo dos profissionais não favorece a capacidade de oferecer atenção integral, fundamental para viabilizar a integralidade na atenção à saúde conforme a proposta do SUS.

Para alcançar os objetivos de extensão de cobertura de assistência, adoção de novos modelos de atençáo, com foco no trabalho em equipe e em açóes 
de promoção e vigilância em saúde são necessários profissionais generalistas, cuja formação requer projetos pedagógicos capazes de atualizar conhecimentos, introduzir novas tecnologias, desenvolver a capacidade de trabalho crítico e multiprofissional [8].

A educação passa por um processo de mudança de paradigma que implica a necessidade de redefinição do papel das instituiçóes de ensino, bem como dos docentes e discentes no cenário educacional. Busca-se, portanto, a superaçáo das contradiçóes originadas nas tendências teóricas que fundamentam o processo educacional dominante, pela inserção de novas estratégias de ensino que favoreçam a formação de um perfil profissional capaz de responder às necessidades sociais da saúde [9].

Um aspecto importante da formação diz respeito à visão que se tem do trabalhador em saúde, não como um simples insumo no conjunto de recursos necessários ao desenvolvimento do trabalho em saúde, dentro da lógica de custo-benefício, como apenas um instrumento para produção de serviços, mas de maneira ampliada como um agente participativo no processo de trabalho, transformador, protagonista do processo de produção de serviços cujo objetivo do trabalho se volta para o cuidado em suas múltiplas dimensóes [10].

Quanto à reorientação da educação em saúde, há necessidade de reversão da matriz de pensamento e práticas centradas em determinantes externos (interesses capitalistas, mercado de trabalho, política de saúde do estado, organizaçáo dos serviços de saúde) e internos (desintegração básico-profissional, conservadorismo docente, desarticulação ensino-serviço) para opçóes e propostas factíveis/viáveis, capazes de introduzir inovaçóes que contenham potencial de fortalecer mudanças nas práticas profissionais e nos processos de trabalho [2].

As transformações dos cursos de graduação e, por conseguinte, dos futuros profissionais perpassam por questôes relativas: ao papel das instituiçóes de ensino e sua inserção na comunidade, sua responsabilidade social, a qualificação dos docentes e seu preparo para mudanças no sentido de vencer a dicotomia entre o pensar e o fazer, ao distanciamento dos serviços de saúde, ao tecnicismo e ao direcionamento da formação dos profissionais em consonância com o SUS e a construçáo coletiva do projeto pedagógico, que deve estar em permanente (re)construção com participação de docentes, discentes e enfermeiros de serviços de saúde [11].
Embora a Constituição determine a competência do SUS para ordenar a formação de recursos humanos, esse preceito não tem se traduzido plenamente em uma prática institucional, uma vez que os instrumentos de poder e de articulação para orientar o processo de formação e distribuição de recursos humanos que o sistema dispóe não têm sido utilizados em sua totalidade. Ou seja, ainda hoje a articulação entre o setor saúde e educaçáo é bastante frágil e muitas instituições de ensino formam futuros profissionais a partir de projetos políticos pedagógicos que não estão embasados nas diretrizes e princípios do SUS [12].

Em uma perspectiva de favorecer a integraçáo e articulação de açóes dos Ministérios da Saúde e da Educação, em 2005, estabeleceu-se uma política articulada de educação em saúde institucionalizada pela Portaria Interministerial no. 2118, de 03 de Novembro de 2005, que instituiu parceria entre o Ministério da Educação e o Ministério da Saúde para cooperação técnica na formação e desenvolvimento de recursos humanos na área de saúde; como conseqüência emergiu o Programa Nacional de Reorientação da Formação Profissional em Saúde - Pró-Saúde - para os cursos de Graduação em Medicina, Enfermagem e Odontologia [13]. Esse Programa tem-se constituído em mais uma iniciativa para reorientar o processo de formaçáo destes profissionais de modo a oferecer à sociedade profissionais habilitados para responder às necessidades da populaçáo brasileira e à operacionalizaçáo do SUS [14].

Entende-se que as iniciativas governamentais e legais para favorecer a articulação entre saúde e educação são de extrema importância, mas não são suficientes por si só. As transformaçôes nas áreas de educação e da saúde precisam acontecer em processos coletivos, com participação responsável e ativa dos atores envolvidos, fazendo-se necessário investir fortemente nos trabalhadores/profissionais da saúde como uma das estratégias para viabilizar a consolidação do SUS. Neste sentido, faz-se necessário pensar as bases que norteiam a formação dos enfermeiros.

\section{A formação do enfermeiro}

Nas discussões acadêmicas sobre as perspectivas da educação em enfermagem emerge o desafio da formação de profissionais com potencial de ação transformadora do cenário de saúde vigente, sur- 
gindo como alternativa a busca constante de novas estratégias, principalmente através da reformulação curricular, no sentido de possibilitar a formação comprometida com a realidade social [15]. Porém, o panorama da formação profissional ainda evidencia a baixa integraçáo ensino-serviço de saúde, a dicotomia entre teoria e prática, área básica e área clínica, em cursos estruturados em modelos curriculares pouco integrados e dinâmicos, muitas vezes distantes da realidade social do sistema de saúde.

A partir da elaboração de um Projeto Político Pedagógico, as instituiçóes de ensino definem sua estrutura curricular, objetivos de curso, critérios de avaliação, estrutura de recursos materiais e humanos necessários e apresentam uma proposta para formação de enfermeiros. Um projeto pedagógico consiste em uma proposta integrada de trabalho, na qual devem estar descritos conjuntos de habilidades cognitivas, afetivas e psicomotoras que se pretende desenvolver em uma determinada clientela, bem como referenciais a ela associados e a metodologia a ser adotada, incluindo formas de ensino e de avaliação [16].

Faz-se necessário que os cursos incorporem, em seus projetos políticos pedagógicos, o arcabouço teórico do SUS, valorizando ainda postulados éticos, a cidadania, a epidemiologia e o processo saúde/ doença/cuidado, no sentido de garantir a formação de acordo com referenciais de qualidade; inovando ao estimular a inserção precoce e progressiva do estudante no cenário do SUS, o que lhe proporcionará conhecimento e compromisso com a realidade de saúde de seu país e regiáo [13].

A implantação das Diretrizes Curriculares $\mathrm{Na}$ cionais para o Ensino da Enfermagem propóe uma importante mudança no campo da educação, indica que os currículos devem ser integrados, construídos coletivamente, buscando formar profissionais com habilidades e competências para uma atuação críti$\mathrm{ca}$, reflexiva frente às reais necessidades de saúde da população, identificadas por indicadores epidemiológicos e socioeconômicos. A articulação com serviços de saúde favorece a formação de profissionais com ênfase na promoção, prevenção, recuperação e reabilitação de saúde ao mesmo tempo em que pode possibilitar maior relevância social para os centros formadores, tanto do ponto de vista da pesquisa (produção de conhecimentos) quanto da própria formação em si [17].

As Diretrizes Curriculares Nacionais do Curso de Graduação em Enfermagem delineiam o perfil do egresso do curso como enfermeiro generalista, humanista, crítico, reflexivo ou, enfermeiro com licenciatura em Enfermagem capacitado para atuar na educação Básica e na educação Profissional em Enfermagem; estabelece seis grandes habilidades e competências para as quais o enfermeiro deve ter conhecimentos: atenção à saúde, tomada de decisões, comunicação, liderança, administração e gerenciamento, educação permanente; institui o estágio supervisionado nos dois últimos semestres do curso e estabelece o projeto pedagógico, construído coletivamente, centrado no estudante como sujeito de aprendizagem, apoiado no professor como facilitador e mediador do processo de ensinoaprendizagem, articulando ainda ensino, pesquisa e extensão/assistência [17].

Entretanto, embora as Diretrizes Curriculares dos Cursos de Graduação em Enfermagem representem um movimento para tornar a formação mais dinâmica, construída coletivamente e articulada ao sistema de saúde, entende-se que por si só não garantem que a prática sofra modificaçóes, porém, é um elemento norteador de um processo de transformação, que deve ser contínuo.

A idéia de construção coletiva de uma proposta pedagógica emerge nos espaços de discussão acerca da graduação em enfermagem no Brasil. Não obstante muitos cursos ainda esbarrem em dificuldades tanto na etapa de construção das propostas quanto na sua implementação, seja por questôes relativas à estrutura educacional ou por dificuldades com os envolvidos no processo [18].

Em relação às estruturas das instituiçóes de ensino, as dificuldades se concentram em torno da carência de tempo, da escassez de recursos materiais e humanos, da precariedade de infra-estrutura acadêmica e administrativa, da exigência de manutençáo de índices de produtividade para manter a pós-graduação [19]. Quanto aos envolvidos no processo de formação dos enfermeiros, destaca-se a dificuldade com as metodologias de ensino ativas/ problematizadoras, ao não envolvimento efetivo das pessoas no processo educacional e a formaçáo tradicional dos docentes [20].

$\mathrm{Na}$ formação de enfermeiros há necessidade de mudanças viabilizadas por meio: da formação nos próprios cursos, de colegiadas com participação docente e discente na elaboração, aplicaçáo e avaliação do projeto político pedagógico; da postura do docente diante dos conteúdos programáticos, passando a pensar e atuar de forma interdisciplinar 
e de cenários novos de aprendizagem, integrando escola-serviço de saúde-população e articulando teoria e prática no ensino de enfermagem [21].

\section{Conclusão}

Esta reflexão acerca dos aspectos relevantes do processo de formação dos enfermeiros não esgota a temática, entretanto evidencia que a questáo de recursos humanos é um tema central, que não pode ser desarticulado da educaçáo formal e permanente e, ambas, não podem ser desconectadas do sistema de saúde vigente e do processo de produção em saúde.

Embora as normativas ministeriais e Diretrizes Curriculares Nacionais para o Ensino da Enfermagem vigentes definam que a formação profissional deve ser fortemente vinculada ao SUS e aos serviços de saúde, ainda hoje esta não é uma situação vivenciada em grande parte das instituiçóes de ensino. Faz-se presente o desafio de formar profissionais críticos e competentes para atuar positivamente como agentes de transformação, em processos dinâmicos de construção do saber e do cuidado.

A implantação e a operacionalização das novas diretrizes curriculares apontam para a formação de um profissional tecnicamente competente, crítico, comprometido com a saúde da população, havendo uma reordenação do conteúdo teórico-prático e a diversificação dos cenários de ensino-aprendizagem. Assim, configura-se a importância e as possibilidades para que as instituiçóes de ensino atuem efetivamente na consolidação do SUS, formando e transformando profissionais de saúde para práticas individuais e coletivas, além de seu papel de produzir novos conhecimentos articulados à prática.

Para as instituiçóes de ensino cabe a missão de elaborar e operacionalizar coletivamente seus projetos pedagógicos, em um movimento contínuo de construçáo e reconstruçáo de suas propostas de formação dos enfermeiros, considerando não apenas as diretrizes, mas a história da instituição, sua missão, suas potencialidades e dificuldades, inseridas em um contexto social de saúde e educação.

Quanto à formação de recursos humanos em saúde, particularmente os enfermeiros, ainda são pontos críticos:

A articulação incipiente entre órgãos gestores dos sistemas de saúde e instituiçóes de ensino que se reflete em uma formação pouco articulada da prática e dos princípios do SUS;
O descompasso entre a formação dos docentes tendo como base didático-pedagógica a abordagem tradicional e as propostas de abordagens pedagógicas mais ativas, exigindo um processo contínuo de capacitação docente;

Pouco investimento na formação profissional e educação permanente em serviço, ambas articuladas à melhoria de aspectos relacionados à estrutura, organização e processo de trabalho;

Projetos pedagógicos cujas propostas são inovadoras e arrojadas, porém sem a adequada e necessária operacionalização para lhe dar concretude.

Acredita-se que a consolidação da enfermagem enquanto profissão está em constante processo de construção e na atualidade o desafio é garantir a formação de profissionais que possuam atuar positivamente no cenário do SUS.

\section{Referências}

1. Organização Pan-Americana de Saúde (OPAS). Relatório Mundial da Saúde [online]. [citado 2008 Ago 1]. Disponível em URL: http://www.who.int/topics/ injuries/about/en/index.html

2. Ceccim RB, Armani TB, Rocha CF. O que dizem a legislaçáo e o controle social em saúde sobre a formaçáo de recursos humanos e o papel dos gestores públicos, no Brasil. Ciên Saúde Coletiva 2002;7(2):373-83.

3. Biasoto Júnior G. Recursos humanos e qualificaçáo profissional: impasses e possibilidades. Rev Formação 2002;2(5):75-85.

4. Ferreira JM. A municipalização da saúde sob os óculos do ser humano-trabalhador de enfermagem da rede básica de Marília. [Tese]. Ribeirão Preto: Escola de Enfermagem de Ribeirão Preto, Universidade de São Paulo; 2001

5. Chaves LDP. Produção de internações nos hospitais sob gestão municipal em Ribeirão Preto-SP, 1996-2003. [Tese]. Ribeirão Preto: Escola de Enfermagem de Ribeirão Preto, Universidade de São Paulo; 2005.

6. Paim J, Teixeira C. Conjuntura atual e formação de pessoal em saúde: problemas, desafios e oportunidades. Texto elaborado para seminário da Rede Unida, Londrina; 2002.

7. Ceccim RB, Feuerwerker LCM. Mudança na graduação das profissóes de saúde sob o eixo da integralidade. Cad Saúde Pública 2004;20(5):1400-10.

8. Faria R, Viana ALD. Experiências inovadoras de capacitação de pessoal para básica no Brasil: balanças, limites e possibilidades dos pólos. In: Negri B, Faria R, Viana ALD, Recursos humanos em saúde: política, desenvolvimento de trabalho. Campinas: Unicamp; 2002. p.127-59.

9. Silva CC. Competências na prática educativa para constituição da força de trabalho em saúde: um desafio aos educadores [Tese]. São Paulo: Escola de Enfermagem da Universidade de São Paulo; 2003. 
10. Brasil. Ministério da Saúde. André F et al, eds.Observatório de recursos humanos em saúde no Brasil: estudos e análises. Rio de Janeiro: Fiocruz; 2003.

11. Maia MRG, Göettems L. Diretrizes curriculares nacionais e formação em enfermagem: construindo perfis com qualidade política. Relatório final de oficina de trabalho no $54^{\circ}$ Congresso Brasileiro de Enfermagem. Fortaleza; 2002.

12. Fonseca CD, Seixas PHD. Agenda Nacional de recursos humanos em saúde: diretrizes e prioridades. In: Negri B, Faria R, Viana ALD. Recursos humanos em saúde: política, desenvolvimento de trabalho. Campinas: Unicamp; 2002. p.289-322.

13. Instituto Nacional de Estudos e Pesquisas (INEP). A trajetória dos cursos de graduação na área da saúde: 1991/2004. Haddad AE et al, eds. Brasília: Instituto Nacional de Estudos e Pesquisas Educacionais Anísio Teixeira; 2006. 531p.

14. Brasil. Ministério da Educação e Saúde. Portaria n. ${ }^{\circ}$ 2101/GM, de 3 de novembro de 2005. Institui o Programa Nacional de Reorientação da Formação Profissional em Saúde - Pró-Saúde - para os cursos de graduação em Medicina, Enfermagem e Odontologia. [citado 2008 Ago 1]. Disponível em: URL: http://www. abem-educmed.org.br/publicacoes/boletim_virtual/ volume_10/portaria_pro_saude.pdf.
15. Ponce de Leon CGRM. Formação de formadores: a prática educativa em um programa de pós-graduação em enfermagem [tese]. João Pessoa: Universidade Federal da Paraíba; 2005.

16. Souza CBG. O projeto pedagógico como instrumento de participaçáo e qualidade no ensino superior. Araquara: ACL/Unesp; 1995.

17. Conselho Nacional de Educação. Diretrizes Curriculares Nacionais dos Cursos de Graduação em Enfermagem, Medicina e Nutrição. Brasília: CNE; 2001.

18. Backes A, Silva RPG, Rodrigues RM. Reformas curriculares no ensino de graduação em enfermagem: processos, tendências e desafios. Ciência Cuidado e Saúde 2007;6(2):223-30.

19. Fernandes JD, Ferreira SL, La Torre MPS, Santa Rosa DO, Costa HOG. Estratégias para a implantação de uma nova proposta pedagógica na Escola de Enfermagem da Universidade Federal da Bahia. Rev Bras Enfermagem 2003;56(4);392-95.

20. Beck CLC, Budó MLD, Terra MG, Campanogara S, Padoin SMM, Blois JMO. Participação na construção de um projeto político-pedagógico na enfermagem. Rev Bras Enfermagem 2003;56(4);405-8.

21. Oliveira BRG, Schneider JF, Rizzotto MLF, Rodrigues RM. Avaliação e construção de um projeto políticopedagógico para a graduação em enfermagem. Rev Bras Enfermagem 2003;56(4);369-73. 